Br Heart J 1988;60:361

\title{
Correspondence
}

\section{Vasculitis complicating treatment with intravenous anisoylated plasminogen streptokinase activator complex in acute myocardial infarction}

Sir,

We were interested to read the report by Bucknall et al $(1988 ; 59: 9-11)$ on vasculitic reactions after intravenous anisoylated plasminogen streptokinase activator complex (APSAC) in acute myocardial infarction. We report a similar reaction in patients treated with intravenous conventional streptokinase, which is a large component of the APSAC molecule.

Eight to ten days after intravenous streptokinase $\left(1.5 \times 10^{6}\right.$ units infused in one hour) four of 120 patients with myocardial infarction developed purpuric, vasculitic eruptions affecting the extensor surfaces of the legs. These resolved in 48 hours to two weeks. None had evidence of systemic effects. Skin biopsy specimens from the two most severely affected individuals were consistent with focal vasculitis, and direct immunofluorescent studies showed perivascular deposition of C3 and IgA. Urinalysis, autoantibody, and complement studies and indices of renal function were normal in all patients, but two patients had raised concentrations of serum immunoglobulins (one IgA and one IgG). Both these patients developed gammaglobulin paraprotein bands, which on isoelectric focusing were shown to be oligoclonal IgG bands. These abnormalities were not present six weeks later. All our patients had raised erythrocyte sedimentation rates (60 to $102 \mathrm{~mm}$ in the first hour) and a rise in antistreptolysin $O$ titre after administration of streptokinase (from a mean of 80 to $175 \mathrm{U} / \mathrm{l}$ ).

We have evidence that an immune reaction was the basis of this complication, namely an increase in antistreptolysin $O$ titres from a baseline titre consistent with previous exposure to streptococcal protein; the deposition of IgA and C3 in the skin; and oligoclonal IgG bands on isoelectric focusing, which are all features of an immune response to antigenic challenge. ${ }^{1}$ The delayed onset of these features is consistent with an immune complex mediated hypersensitivity reaction, and, although we did not detect circulating immune complexes, they were found in another study. ${ }^{2}$

These reactions occurred despite routine pro- phylaxis with $100 \mathrm{mg}$ hydrocortisone and a single intravenous dose of chlorpheniramine $(10 \mathrm{mg})$. This dose of hydrocortisone does not prevent immediate type hypersensitivity reactions, ${ }^{3}$ and in our patients and others ${ }^{4}$ it did not prevent dèlayed reactions.

In our experience, such complications are rare and without sequelae. Nevertheless, Bucknall's patients, unlike ours, showed multisystem effects, and crescentic glomerulonephritis has been reported after treatment with streptokinase and subsequent streptococcal infection. ${ }^{4}$ Patients treated with streptokinase and APSAC should be monitored closely. As the use of these agents increases in acute myocardial infarction we expect that the numbers of such reactions will increase.

\author{
J D Gemmill, \\ $M$ Sandler, \\ W S Hillis, \\ J Tillman, \\ R Wakeel, \\ Departments of Materia Medica, Biochemistry, and \\ Dermatology, \\ Stobhill General Hospital, \\ Glasgow G21 3UW.
}

\section{References}

1 Sinclair D, Sheehan T, Parrott DMV, Stott DI. The incidence of monoclonal gammopathy in a population over 45 years old determined by isoelectric focussing. Br J Haematol 1986;65:745-50.

2 Manoharan A, Ramsay D, Davis S, Louff R. Hypersensitivity vasculitis associated with streptokinase. Aust NZ J Med 1986;16:815-6.

3 Dykewicz MS, McGrath KG, Davison R, Kaplan KJ, Paterson $R$. Identification of patients at risk for anaphylaxis due to streptokinase. Arch Intern Med 1986;146:305-7.

4 Murray N, Lyons J, Chappell $M$. Crescentic glomerulonephritis: a possible complication of streptokinase treatment for myocardial infarction. Br Heart $J$ 1986;56:483-5. 